\title{
¿Protege derechos fundamentales el Tribunal Constitucional chileno?
}

\author{
María Beatriz Arriagada Cáceres*
}

\section{RESUMEN}

Utilizando dos distinciones que la teoría analítica del derecho ha puesto de relieve ("normas regulativas y normas de competencia" y "actos materiales y actos normativos"), este artículo critica la general consideración de los denominados derechos fundamentales civiles como una especie de derecho subjetivo. Mediante la deconstrucción de las disposiciones que los consagran, se identifican los dos diferentes significados que estos tienen. Esto permite explicitar la teoría que subyace a la práctica interpretativa del Tribunal Constitucional y, a partir de ello, refutar la extendida comprensión de aquel como un órgano protector de derechos fundamentales, a la vez que justificar la agrupación de los llamados derechos civiles y los llamados derechos políticos bajo una misma categoría analítica.

Derechos fundamentales - Tribunal Constitucional - derechos civiles y políticos

\section{Does the Chilean Constitutional Court protect fundamental rights?}

\begin{abstract}
This article uses two distinctions that analytic theory of law has highlighted ("regulative norms and norms of competence" and "material and normative acts") to criticize the general understanding of the so-called civil rights as a kind of subjective right. Two different meanings of this rights are found by deconstructing the provisions that entrench them. This contribute to explain the theory that underlies the interpretative practice of the Chilean Constitutional Court and, on this basis, to refute the widespread understanding that consider such court as a protector of fundamental rights at the same time that allow to group the so-called civil and political rights under the same analytical category.
\end{abstract}

Fundamental rights - constitutional court - civil and political rights

* Licenciado en Derecho Pontificia Universidad Católica de Chile. Doctor en Derecho Universidad de Chile. Profesora de Teoría del Derecho de la Universidad Diego Portales, Santiago de Chile. Correo electrónico: maria.arriagada@udp.cl; mbeatriz.arriagada@gmail.com.

Artículo recibido el 30 de agosto de 2014 y aceptado para su publicación el 27 de marzo de 2015. 


\section{Delimitación Del tema}

A tendido que la expresión "derechos fundamentales" se usa en varios y diferentes sentidos, parto de la base que ellos son posiciones jurídicas subjetivas en que los individuos se encuentran en relación con el Estado ${ }^{1}$ que, dirigidas a la protección de bienes considerados especialmente importantes, se fundamentan en normas jurídicas positivas, específicamente en la Constitución, asumiendo que esta es, por definición, rígida ${ }^{2}$. Y aunque entiendo que, bajo esta denominación, también deben incluirse los llamados derechos políticos y los llamados derechos sociales, el análisis de este trabajo se circunscribe a los denominados derechos civiles.

Discutiré la general aceptación acrítica de estos últimos como una especie de derecho subjetivo y, a partir de ello, la común comprensión de la actividad que realiza el Tribunal Constitucional chileno (en adelante TC), especialmente cuando conoce y falla las acciones de inconstitucionalidad e inaplicabilidad. La explicación que, a cambio, se propone no tiene pretensiones normativas en cuanto solo intenta explicitar la teoría que subyace a la práctica interpretativa del $\mathrm{TC}^{3}$. Si bien esta discusión supone una crítica hacia la dogmática constitucional, el blanco al que principalmente apunto es la teoría del derecho.

\section{Dos Distinciones Relevantes De LA TEORÍA ANALÍtica DEL DERECHO}

\subsection{Normas regulativas y normas de competencia}

El aporte más significativo de la teoría analítica del derecho ha sido mostrar que las normas de competencia o respecto de la producción jurídica son diferentes e irreductibles a las normas regulativas o prescriptivas.

Entender esto supone primeramente entender que una norma no es equivalente a los signos en que ella es formulada. Se deben distinguir las normas de los enunciados,

\footnotetext{
${ }^{1}$ Excluyo entonces de su referencia los llamados "derechos colectivos" y los derechos fundamentales vistos desde la perspectiva de su "eficacia horizontal".

2 Acerca de la rigidez de la Constitución entendida como un rasgo definitorio de la misma, ver por ejemplo, Ferrajoli, L., "Las garantías constitucionales de los derechos fundamentales", en Doxa, No 29, 2006, p. 23 y Guastini, R., Estudios de teoría constitucional, Fontamara, México D.F., 2001, pp. 188-189.

${ }^{3}$ Aunque también es aplicable a cualquier orden jurídico democrático cuya constitución (rígida): (i) declare asegurar a los individuos la protección de ciertos bienes bajo la denominación de derechos fundamentales, esenciales, constitucionales u otras semejantes, que básicamente corresponden a los típicamente llamados derechos civiles; como el derecho a la vida, la libertad de conciencia y el derecho de propiedad; (ii) atribuya competencia a un tribunal para controlar la constitucionalidad de las normas infraconstitucionales; (iii) confiera a los individuos la potestad de activar al menos alguna instancia de ese control; y (iv) consagre los llamados "derechos políticos" (al sufragio y a optar a cargos públicos de elección popular).
} 
disposiciones o formulaciones en que ellas se expresan ${ }^{4}$. Y en segundo lugar, comprender que el sentido de uno o más enunciados normativos no depende de su forma lingüística, sino del modo en que se emplean las palabras y oraciones ${ }^{5}$. No interesa la forma lingüística adoptada, sino el sentido del acto que produce la norma ${ }^{6}$ y la práctica interpretativa que se verifica a partir de los signos, pues estos solo pueden servir de guía en la medida que exista un uso estable, una práctica ${ }^{7}$.

En sintonía con la sugerencia wittgensteiniana en donde hay una captación de una regla que se manifiesta, de caso en caso de aplicación, en lo que llamamos "seguir la regla" y en lo que llamamos "contravenirla" , el argumento mejor formulado en contra de los intentos de equiparar las normas de competencia con las normas regulativas se funda precisamente en la distinción de las consecuencias que se siguen de la observancia e inobservancia de unas y otras. Mientras de la observancia e inobservancia de las normas de competencia se sigue, siempre y respectivamente, la validez y la invalidez de las normas producidas en aplicación de aquellas normas, tales consecuencias no se siguen nunca de la respectiva observancia e inobservancia de las normas regulativas?

${ }^{4}$ Las formulaciones de las normas pertenecen al lenguaje; son los signos o símbolos (las palabras y oraciones) usadas al enunciar (formular) las normas; Von Wright, G., Norma y acción. Una investigación lógica, Tecnos, Madrid, 1970 (original de 1963), p. 109.

${ }^{5}$ Es el uso de la expresión y no su aspecto lo determinante; Von Wright, G., Op. cit., 1970 (1963), p. 117. Mientras los signos son meros indicadores de lo que se hace cuando se emiten las palabras, las normas son el resultado de cierto uso del lenguaje. Esta es la concepción expresiva de las normas, que se opone a la concepción hilética, donde las normas son significados, en sentido semántico, de las oraciones normativas; Alchourrón, C y Bulygin, E, "La concepción expresiva de las normas", en Alchourrón, C., y Bulygin, E., Análisis lógico y derecho, CEPC, Madrid, 1991 (original de 1981), pp. 122-123 A este respecto resulta perfectamente aplicable al lenguaje normativo la distinción wittgensteiniana entre "gramática superficial" y "gramática profunda", así como la tesis, en que las palabras y las oraciones son herramientas que pueden usarse de diferentes modos; ver Wittgenstein, L., Investigaciones filosóficas, Crítica, Barcelona, 2008 (original de 1953), especialmente los parágrafos 7, 11, 20-23, 43, 81, 421 y 664. Relativo a la diferencia entre el acto (locucionario) de decir algo y el acto (ilocucionario) que se ejecuta al decir algo y determina la manera en que se está usando la locución, ver Austin, J.L., Cómo hacer cosas con palabras, Paidós, Barcelona, 1971 (original de 1962), p. 145.

${ }^{6}$ Kelsen, H., Teoría pura del Derecho (2a edición), Porrúa, México D.F.,1991 (original de 1960); pp. 84-85.

${ }^{7}$ Ver Wittgenstein, L, Op. cit., 2008 (1953), parágrafos 199 y 202.

${ }^{8}$ Wittgenstein, L, Op. cit., 2008 (1953), parágrafo 201. De otra forma no se explicaría que podamos reconocer cuando las normas han sido violadas y la capacidad que ellas tienen de cubrir nuevos casos; ver Searle, J., Actos de habla. Ensayo de Filosofía del Lenguaje, Cátedra, Madrid, 2007 (original de 1969), p. 51.

${ }^{9}$ Según Hart, cuando se trata de reglas que imponen deberes es posible distinguir claramente la regla que obliga a determinada conducta de la sanción establecida para el caso de su transgresión; mientras cuando se trata de una regla que confiere poderes no es lógicamente posible distinguir la regla (que establece condiciones para la validez jurídica) de la nulidad; esta es parte de la regla misma de este tipo de una manera distinta a como el castigo está ligado a una norma que impone deberes; Hart, H.L.A., El concepto de derecho, Abeledo-Perrot, Buenos Aires, 2009 (original de 1961), pp. 43-44. En el mismo sentido, Bulygin, E., "Sobre las normas de competencia”, en Alchourrón, C. y Bulygin, E., Análisis lógico y derecho, CEPC, Madrid, 1991 (original de 1988), pp. 487-489 y 495-496. Por lo demás, las normas de competencia tampoco pueden ser asimiladas a las normas permisivas porque en el caso de estas últimas tampoco tiene sentido hablar de nulidad; Alchourrón, C y Bulygin, E., "Definiciones y normas", en Análisis lógico y derecho, CEPC, Madrid, 1991 (original de 1983), p. 462. En contra, esto es, a favor de la posibilidad de asimilar las normas de 
Hohfeld reconoce implícitamente la distinción entre normas regulativas y normas de competencia cuando distingue el concepto de derecho subjetivo o pretensión del concepto de potestad o competencia Mientras el indicio o pista que en el lenguaje jurídico ordinario sugiere una limitación de la expresión "derecho" (subjetivo) en la dirección de un significado definido y apropiado consiste en el "deber correlativo", una "potestad" puede definirse como la posición en la que se encuentra el individuo de cuya voluntad depende decisivamente la modificación de determinadas relaciones jurídicas ${ }^{10}$.

En el significado que Hohfeld considera definido y apropiado para la expresión derecho subjetivo, coincidente con el concepto de "derecho subjetivo reflejo" definido por Kelsen ${ }^{11}$, está implicado que los derechos subjetivos no son derechos activos (a hacer algo) sino derechos pasivos ${ }^{12}$ que, conferidos por normas regulativas, obligan negativa o positivamente a otros ${ }^{13}$.

Algo distinto es que al titular de un derecho subjetivo de este tipo conferido por una norma regulativa ${ }^{14}$ se le confiera, mediante una norma de competencia, ${ }^{15}$ el poder de poner en movimiento, mediante una acción, el procedimiento destinado a reconocer la falta de cumplimiento de la obligación por el deudor, y por tanto, el poder de participar en la producción de la norma jurídica individual de la sentencia judicial en la que se estatuye una sanción concreta por dicho incumplimiento. En esta situación, el individuo tiene lo que Kelsen llama un "derecho subjetivo en sentido técnico"16, que no es otra cosa que una conjunción de los conceptos hohfeldianos de derecho subjetivo y

competencia con las normas permisivas, ver por ejemplo, Von Wright, G., Op. cit., 1970 (1963), pp. 195211; Raz, J., Razón práctica y normas, CEPC, Madrid, 1991 (original de 1975), pp. 118-121 y Nino, C.S., Introducción al análisis del derecho, Astrea, Buenos Aires, 1980, pp. 222-224.

${ }^{10}$ A su parecer, la posición pasiva denominada "deber" permite definir la posición de "derecho" por ser su correlativo, la de "libertad" por ser su opuesto, y la de "no derecho" por ser el opuesto de su correlativo (derecho) y el correlativo de su opuesto (libertad). A su turno, la posición activa de "potestad" o "competencia"permite definir la posición de "sujeción" por ser su correlativo, la de "incompetencia” por ser su opuesto, y la de "inmunidad” por ser el opuesto de su correlativo (sujeción) y el correlativo de su opuesto (incompetencia); Hohfeld, W., Conceptos jurídicos fundamentales, Fontamara, México D.F., 1992 (original de 1913), pp. 45-81.

${ }^{11}$ Así lo considera, por ejemplo, Cruz Parcero, J, El concepto de derecho subjetivo, Fontamara, México, 2007 , p. 37. Acerca del concepto del derecho subjetivo en sentido técnico, ver Kelsen, H., Op. cit., 1991 (1960), pp. 139-142.

12 Tener un derecho pasivo significa tener derecho a que se respete una situación o a recibir algo por parte de otro; Cruz Parcero, J, Op. cit., 2007, p. 24.

${ }^{13}$ Por ello Kelsen critica que el "ejercicio" de los derechos sea identificado con la conducta correspondiente del individuo en cuyo respecto existe la obligación y rechaza la distinción entre derechos personales y reales; Kelsen, H., Op. cit., 1991 (1960), pp. 140 y143.

${ }^{14}$ Una que obliga a cierta conducta enlazando a la contraria una sanción; Kelsen, H., Op. cit., 1991 (1960), pp. 140 .

${ }^{15}$ Una norma facultativa perteneciente a la categoría de las "normas no independientes" porque solo determina una de las condiciones a las que una norma independiente enlaza el acto coactivo; ver Kelsen, H., Op. cit., 1991 (1960), p. 68.

${ }^{16}$ Kelsen, H., Op. cit., 1991 (1960), pp. 146-149 y 152. 
potestad $^{17}$. Un derecho igualmente pasivo que, a diferencia del simple derecho reflejo, se encuentra judicialmente garantizado ${ }^{18}$.

Asumiendo que la "competencia jurídica" es un requisito necesario y suficiente de la "validez jurídica" ${ }^{19}$, la primera puede definirse como la posibilidad que ciertas normas de un sistema jurídico atribuyen a un sujeto de producir, en las condiciones definidas por esas mismas normas, normas jurídicas válidas. En esta "posibilidad" se incluye la de participar en la producción de normas jurídicas válidas ${ }^{20}$. Las "normas jurídicas de competencia" (o respecto de la producción jurídica) pueden definirse como aquellas que, en un sistema jurídico, definen las competencias o potestades para producir normas jurídicas válidas ${ }^{21}$. Y Ellas no solo comprenden a las que confieren las competencias para producir normas jurídicas válidas, sino también a las que condicionan el ejercicio de tales competencias ${ }^{22}$. Desde este punto de vista, se puede afirmar que una norma es jurídicamente válida cuando ha sido producida de conformidad con las normas (de competencia) que, en un sistema jurídico, definen las potestades o competencias para producirla $^{23}$.

${ }_{17}$ Por lo mismo, cuando apoyándose en la caracterización kelseniana del derecho subjetivo en sentido técnico, Atria define el derecho subjetivo como la potestad de decidir si la obligación de otro será o no coactivamente exigida, puntualiza estar empleando el concepto de potestad en el sentido de Hohfeld; Atria, F., "Existen los derechos sociales", en Doxa, Discusiones: Derechos sociales, No 4, 2004, pp. 22-23 y nota $\mathrm{N}^{\circ} 19$ del mismo trabajo.

${ }^{18}$ Referente a la distinción entre los derechos y su garantía judicial, ver por ejemplo Alexy, R., Teoría de los derechos fundamentales, CEPC, Madrid, 2007 (original de 1984), p. 456 y Guastini, R., Distinguiendo. Estudios de teoría y metateoría del derecho, Gedisa, Barcelona, 1999 (original de 1996), p. 185.

${ }^{19}$ Esto puede discutirse y justificarse, pero no lo haré aquí. Una posición diferente puede verse, por ejemplo, en Ferrer, J., Las normas de competencia. Un aspecto de la dinámica jurídica, CEPC, Madrid, 2000, pp. 135-139.

20 Siguiendo a Kelsen, el concepto de competencia, que tradicionalmente se reserva para aludir al poder jurídico atribuido a los órganos públicos (legislativos, judiciales o administrativos) de producir normas generales o individuales, también comprende la capacidad que el orden jurídico confiere a los individuos de participar en la producción de normas generales (como en el caso de los "derechos políticos") o normas individuales (como en el caso de la llamada "capacidad procesal”); Kelsen, H., Op. cit., 1991 (1960), pp. 158161 y 151-157. De hecho, el término "competencia" no está generalmente reservado para los órganos jurídicos en el discurso de la teoría del derecho; ver por ejemplo Ross, A. "Sobre los conceptos de 'Estado’ y ‘Órganos del Estado' en Derecho Constitucional”, en Ross, A, El concepto de validez y otros ensayos, Fontamara, México, 1991 (original de 1961), pp. 77-78; Cruz Parcero, J., Op. cit., 2007, pp. 35-36; Atienza, M y Ruiz Manero, J., Las piezas del derecho, Ariel, Barcelona, 2004, p. 83. En la misma línea, Hohfeld, W., Op. cit., 1992 (1913), pp. 71, admite que las potestades del agent son comparables a las de los funcionarios públicos.

${ }^{21}$ Para una sólida defensa del carácter definicional de las normas de competencia, ver Alchourrón, C y Bulygin, E., Op. cit., 1983, pp. 461-463.

${ }^{22}$ Ver por ejemplo, Prieto Sanchís, L., Apuntes de Teoría del Derecho, Trotta, Madrid, 2009, pp. 76-78 y Guastini, R, Op. cit., 1999 (1996), pp. 337-339.

${ }^{23}$ En este sentido, la validez de una norma hace referencia a su creación regular y depende de la conformidad con normas de jerarquía superior; Orunesu, C., Positivismo Jurídico y sistemas constitucionales, Marcial Pons, Madrid, 2012, pp. 119-120, por lo que su definición corresponde a lo que Kelsen denomina el fundamento de validez de una norma; Kelsen, H., Op. cit., 1991 (1960), pp. 201-208. 


\subsection{Actos materiales y actos normativos}

Otra importante distinción que la teoría del derecho ha puesto de relieve y que está relacionada con la de "normas regulativas y normas de competencia", es la "actos materiales y actos normativos".

Los actos materiales, naturales o informales pueden ser solamente supuestos de hecho de normas y se caracterizan porque producen dos tipos de efectos: (i) efectos de hecho desincentivados o incentivados por el derecho mediante prohibiciones y obligaciones, y (ii) efectos de derecho (sancionatorios o satisfactorios) preestablecidos por las normas que los regulan. A su turno, los actos normativos, artificiales o formales, no son simplemente supuestos de hecho de normas sino también actos aplicadores de normas. Ellos producen solamente efectos de derecho condicionados por las normas que lo prevén a la observancia de ciertas formas en el ejercicio de determinados poderes $^{24}$. En términos searlianos, los actos materiales son hechos brutos; su existencia no depende lógicamente de la existencia de ninguna regla. Y los actos normativos son hechos institucionales; su existencia es lógicamente dependiente de la existencia de las llamadas reglas constitutivas ${ }^{25}$.

La distinción anotada es importante. En primer lugar, porque la validez y la invalidez no se predican, en estricto sentido, de las normas, sino de los actos normativos que las producen aplicando normas de competencia. En segundo lugar, porque ni validez ni la invalidez pueden predicarse de actos materiales, cuya existencia no depende de la existencia de ninguna norma.

El modelo de análisis de Hohfeld permite captar bien esta distinción, así como su relación con la diferencia entre normas de competencia y normas regulativas: (i) mientras las relaciones de "potestad-sujeción" se refieren siempre a la posibilidad de realizar actos normativos en aplicación de normas de competencia, una relación de "inmunidadincompetencia" connota la imposibilidad de realizar tales actos porque se fundamenta en la ausencia de normas de competencia; y (ii) mientras las relaciones de "derecho-deber" pueden referirse a la exigencia de realizar o no realizar actos materiales que son supuestos de hecho de normas regulativas ${ }^{26}$, una relación de "libertad-no derecho" puede connotar la inexistencia de la exigencia de realizar este tipo de actos, pues se fundamenta en la ausencia de normas de regulativas.

${ }^{24}$ Ferrajoli, L., Principia iuris. Teoría del derecho y de la democracia, Trotta, Madrid, 2011 (original de 2007), pp. 464-465.

${ }^{25}$ Searle, J., Op. cit., 2007 (1969), pp. 58-61 y La construcción de la realidad social, Paidós, Barcelona, 1997 (original de 1995), pp. 44-46.

${ }^{26}$ En tanto la posición pasiva denominada "deber" a menudo consiste en una exigencia de realizar o no una determinada conducta material. 


\section{Planteamiento Del Problema}

Pese a la inteligencia invertida en la formulación de estas distinciones, la teoría del derecho suele ignorarlas a la hora de analizar los llamados derechos fundamentales civiles.

Es muy frecuente que se afirme que: (i) los derechos fundamentales civiles son el reflejo de obligaciones jurídicas de abstención que el Estado debe cumplir, y (ii) la violación de tales obligaciones es causa de invalidez general (inconstitucionalidad) o particular (inaplicabilidad) ${ }^{27}$ de las normas jurídicas producidas por las autoridades públicas ${ }^{28}$.

La primera de estas afirmaciones es problemática porque la consideración acrítica de los llamados derechos civiles como derechos subjetivos de abstención impide justificar satisfactoriamente el hecho que sean comúnmente agrupados junto a los denominados derechos políticos. Como estos últimos no son derechos subjetivos que reflejan obligaciones del Estado sino potestades o competencias que los órdenes jurídicos democráticos confieren a los individuos para participar en la creación, modificación o extinción de normas jurídicas ${ }^{29}$, resulta difícil vincularlos con los derechos civiles ${ }^{30}$. Volveré acerca de este problema al final de este trabajo.

La segunda de las afirmaciones formuladas es incorrecta en cuanto pasa por alto que de la inobservancia de normas regulativas que imponen obligaciones y confieren derechos no se sigue la invalidez (general o particular) de normas.

${ }^{27}$ Como la "aplicabilidad jurídica" de una norma, entendida como la correlación entre dicha norma y su aplicación afirmada como existente en el presente (Bulygin, E., "El concepto de eficacia" en VV.AA, Validez y eficacia del derecho, Astrea, Buenos Aires, 1965, pp. 42-47) se juzga con referencia a las mismas normas conforme a las cuales se ha juzgado su validez, la aplicabilidad de una norma, en este sentido, no es otra cosa que su validez singular mientras su inaplicabilidad es su anulación para determinado caso; Kelsen, H., “QQuién debe ser el defensor de la Constitución?”, en Schmitt, C y Kelsen, H., La polémica Schmitt/Kelsen sobre la justicia constitucional: El defensor de la Constitución versus ¿Quién debe ser el defensor de la Constitución?, Tecnos, Madrid, 2009b (original de 1931), pp. 313-314. La diferencia reside, se supone, en que el juicio de validez es concreto.

${ }^{28}$ Ver Guastini, R, Op. cit., 1999 (1996), pp. 188-189 y 336-337; Orunesu, C, Op. cit., 2012, pp. 103 y 105 y Prieto Sanchís, L. "La limitación de los derechos fundamentales y la norma de clausura en el sistema de libertades", en Derechos y libertades, No 8, enero/junio 2000, pp. 437 y 445. En la misma línea, aunque precisando que la infracción de las señaladas obligaciones "debiera” ser causa de validez jurídica, Ferrajoli, L., "Derechos fundamentales", en VV.AA, Los fundamentos de los derechos fundamentales, Trotta, Madrid, 2007 (original de 2001); pp. 34-35.

${ }^{29}$ Kelsen, H., Op. cit., 1991 (1960), pp. 150-151. Una cuestión diferente es que para poder afirmar que los derechos políticos así entendidos existen en un ordenamiento jurídico y que este es, en consecuencia, democrático, no basta que la Constitución así lo declare. Es necesario que el Estado se abstenga de impedir su ejercicio y provea los medios jurídicos y materiales que lo hagan posible. Pero admitir esto no equivale a afirmar que estas posiciones jurídicas son derechos subjetivos que reflejan obligaciones estatales de abstención y de prestación.

${ }^{30}$ El problema es sugerido, aunque sin identificar su causa, por Ruiz-Tagle, P., "Una visión democrática y liberal de los derechos fundamentales para la constitución chilena del bicentenario”, en Bordalí, A (ed.), Justicia Constitucional y derechos fundamentales. Lexis Nexis, Santiago, 2006, p. 107 y "Un proyecto constitucional para la generación del bicentenario: Igualdad y derechos sociales y económicos en Chile", en Revista de Derecho y Humanidades, $\mathrm{N}^{\circ} 15,2009$, pp. 24-25. 
Aunque parte de nuestra dogmática constitucional ha problematizado el significado de los derechos fundamentales cuestionando su consideración como derechos subjeti$\operatorname{vos}^{31}$, dicho esfuerzo no se ha traducido en una revisión de la asentada comprensión del TC como un órgano que protege derechos ${ }^{32}$. Y esto a pesar que las sentencias de este tribunal producen efectos que no podrían derivarse de la inobservancia de normas que confieren derechos e imponen obligaciones, sino exclusivamente de la inobservancia de normas relativas a la producción jurídica.

Si la invalidez general o particular de las normas producidas por las autoridades públicas se juzga de conformidad con las normas que confieren los llamados derechos fundamentales civiles, estas normas tendrían que ser de competencia, y en cuanto tales, diferentes e irreductibles a las normas regulativas que imponen obligaciones y confieren derechos subjetivos. Salvo que se acepte que una norma de competencia pueda ser, al mismo tiempo, regulativa.

Searle parece sugerir que esto es posible cuando afirma que las reglas regulativas regulan una actividad cuya existencia es lógicamente independiente de las reglas, y que las reglas constitutivas constituyen (y también regulan) una actividad cuya existencia es lógicamente dependiente de las reglas ${ }^{33}$. La cuestión es relevante porque, como según Searle, las reglas constitutivas se diferencian de las puramente regulativas porque crean o definen nuevas formas de conducta y pueden aparecer como una verdad analítica basada en el significado de la actividad que ellas definen ${ }^{34}$, las normas de competencia pueden considerarse una especie de las reglas constitutivas ${ }^{35}$.

Desde este punto de vista, una conducta definida por una norma de competencia (constitutiva) podría ser regulada por la misma norma que entonces sería, a la vez, regulativa ${ }^{36}$. Pero lo que en realidad ocurre es que es perfectamente posible que una

${ }^{31}$ Ver por ejemplo, Gómez, G., Derechos fundamentales y Recurso de protección, Ediciones Universidad Diego Portales, Santiago, 2005 pp. 19-31 y Aldunate, E., Derechos fundamentales, Legal Publishing, Santiago, 2008, pp. 105-124, cuyo esfuerzo se articula a partir de una crítica a la pobreza las construcciones dogmáticas acerca de derechos fundamentales en nuestro país. Ruiz-Tagle, por su parte, señala expresamente que el concepto de derechos fundamentales es una categoría dogmática del derecho positivo diferente de la noción de derecho subjetivo, pero no consigue formular una definición alternativa clara; Ruiz-Tagle, P., Op. cit., 2006, p. 126.

32 Se afirma, sin ningún matiz, que el TC protege los derechos de las personas; Zapata, P., Justicia constitucional. Teoría y práctica en el derecho chileno y comparado, Editorial Jurídica de Chile, Santiago, 2008, p. 535. Se afirma que una parte importante del control de fondo que realiza el Tribunal Constitucional y que se destina a asegurar que los mandatos, prohibiciones o permisos establecidos en las leyes y otras regulaciones no contradigan las disposiciones constitucionales tiene como objetivo la protección de derechos; Mac Clure, L. "Tribunal Constitucional y los derechos. La discusión pendiente", en Sierra, L y Mac-Clure, L, Frente a las mayorías. Leyes supramayoritarias y Tribunal Constitucional en Chile, CEP, CIEPLAN, Libertad y Desarrollo, Proyectamérica y PNUD, Santiago, 2011, pp. 186-188.

33 Searle, J., Op. cit., 2007 (1969), p. 43.

${ }^{34}$ Ibid., p. 44-45.

${ }^{35}$ Atinente a las normas de competencia como reglas constitutivas, ver por ejemplo Atienza, M y Ruiz Manero, J., Op. cit., 2004, pp. 85-86; Guastini, R, Op. cit., 1999 (1996), p. 99; Ferrer, J., Op. cit., 2000, p. 135.

${ }^{36}$ Aunque Searle no aclara cómo es posible que las reglas constitutivas sean, por un lado, definiciones o enunciados analíticos basados en el significado de los términos así definidos y, por el otro, reglas regulativas de las actividades por ellas definidas; Bulygin, E., Op. cit., 1988, p. 492. Incluso Ross que, en la misma 
conducta definida por una norma de competencia (constitutiva) sea posteriormente regulada por una o más normas regulativas ${ }^{37}$, ya que estas pueden ordenar o permitir tanto conductas naturales como artificiales. Como una regla no es equivalente a los signos en que se expresa, la tesis de Searle puede corregirse o reinterpretarse afirmando que es posible que una misma formulación normativa exprese dos reglas diferentes e irreductibles: una constitutiva, que define una forma de conducta, y una regulativa que manda, prohíbe o permite la conducta definida por la primera.

Se podría entonces interpretar que cuando se afirma que la violación de las obligaciones de abstención correspondientes a los derechos fundamentales civiles produce la invalidez jurídica general (inconstitucionalidad) o particular (inaplicabilidad) de las normas producidas por las autoridades públicas, se está queriendo decir que una misma disposición constitucional expresa dos normas diferentes e irreductibles que atribuyen consecuencias jurídicas diversas a un mismo tipo de conducta.

Esto significa que la misma conducta cuya omisión es condición de la validez de otras normas de conformidad con una norma A (de competencia), ha sido prohibida por una norma B (regulativa), y que ambas normas son expresadas en la misma formulación normativa. Aunque en el tipo de afirmación que se analiza parece más bien sostenerse lo inverso: que la omisión de una conducta que una norma A (regulativa) prohíbe es definida por una norma B (de competencia) como condición de validez de otras normas, y que ambas normas son expresadas en el mismo enunciado normativo.

En alguna de estas dos alternativas parece poder ubicarse la posición de Alexy. A su parecer, el carácter defectuoso de los actos de creación de normas, que caen en el ámbito de la no competencia, podría ser explicado solo a medias si únicamente se cataloga a estos actos como prohibidos. Si en cambio se presupone la existencia tanto de una norma de prohibición como de una norma de competencia negativa, con la ayuda de la primera se puede explicar sin mayor problema la calificación prohibida, y con la ayuda de la segunda la calificación defectuosa ${ }^{38}$.

Esta interpretación de los denominados derechos fundamentales civiles es, sin embargo, incorrecta. Porque aunque es cierto que las disposiciones constitucionales que los consagran expresan dos normas jurídicas diferentes e irreductibles, no es cierto que ambas normas se refieran al mismo tipo de conducta. La teoría del derecho ha olvidado distinguir, esta vez, a los actos materiales de los actos artificiales.

dirección, distingue entre reglas regulativas y constitutivas según la forma en que tales reglas se relacionan con la actividad (natural o no natural) a la que se refieren, descarta que las reglas constitutivas puedan ser a la vez regulativas, al caracterizarlas como reglas no susceptibles de violación; Ross, A., Lógica de las normas, Colmares, Granada, 2000 (original de 1968), pp. 68-73.

${ }^{37}$ De hecho, las potestades pueden ser reforzadas mediante deberes; Hart, H.L.A, Op. cit., 2009 (1961), pp. 37 y 120. Una cosa es conferir un poder (normativo) y otra es regular el ejercicio de ese poder; Atienza, M y Ruiz Manero, L., Op. cit., 2004, p. 84. Esto es diferente a sostener, como Schauer, que las reglas constitutivas pierden su carácter constitutivo dentro de las instituciones previamente definidas o constituidas por ellas; Schauer, F., Las reglas en juego, Marcial Pons, Madrid, 2004 (original de 1991), p. 63.

38 Alexy, R., Op. cit., 2007 (1984), pp. 213-214. Por ello aconseja utilizar la expresión "derecho subjetivo", siguiendo el uso existente, como un concepto general para posiciones muy diferentes para luego, dentro de ese marco, tratar distinciones y llevar a cabo caracterizaciones terminológicas; Ibíd.: 162-214. 


\section{LOS DOS SIGNIFICADOS DE LOS DENOMINADOS DERECHOS FUNDAMENTALES CIVILES}

Mi tesis es que, con miras a la protección de ciertos bienes, las disposiciones constitucionales que consagran los denominados derechos civiles expresan dos tipos de normas jurídicas que, además de ser diferentes e irreductibles, no se refieren al mismo tipo de conducta:

(i) Normas regulativas que confieren a los individuos derechos subjetivos, en cuanto imponen al Estado obligaciones de abstención de cuyo cumplimiento depende la licitud de las actuaciones materiales de las autoridades públicas.

(ii) Fragmentos de normas de competencia que confieren a los individuos potestades de participación política cuyo ejercicio condiciona la validez general o particular de las normas jurídicas producidas por las autoridades públicas.

Las normas regulativas expresadas en las disposiciones que consagran los denominados derechos civiles confieren auténticos derechos subjetivos que reflejan obligaciones estatales negativas. Los titulares de estas posiciones no tienen derecho a que las autoridades públicas se abstengan de producir normas, sino derecho a que ellas se abstengan de realizar actos materiales que pudieren impedir o interferir el disfrute de los bienes que los mencionados derechos protegen. Como los actos materiales no pueden ser válidos o inválidos ni aplicables o inaplicables, sino lícitos o ilícitos, el incumplimiento de las obligaciones que los derechos civiles reflejan constituye un acto ilícito que se encuentra prohibido. Las autoridades públicas que se abstienen de realizar estos actos ilícitos cumplen (no aplican) las normas que los prohíben.

Así considerados, los derechos civiles suelen encontrarse judicialmente garantizados. Esto significa que los sometidos a derecho no solo tienen un derecho subjetivo a que las autoridades públicas se abstengan de realizar actos naturales que les impidan, por ejemplo, expresarse libremente. También tienen un poder jurídico para reclamar frente al incumplimiento de las correspondientes obligaciones estatales, ejercitando una acción de protección o de amparo. Desde esta perspectiva, los derechos civiles son derechos subjetivos en sentido técnico ${ }^{39}$. Y una parte importante del trabajo que realizan las Cortes de Apelaciones y la Corte Suprema cuando conocen y fallan las acciones de protección y de amparo dice relación con su tutela.

El carácter material de las actuaciones cuya licitud depende del cumplimiento de las obligaciones que estos derechos reflejan permite conjeturar que si frente a su

${ }^{39}$ La circunstancia de que sean derechos subjetivos individuales judicialmente exigibles no implica que ellos expresen la negación de que un individuo pueda ser utilizado en beneficio de otro o el reclamo del hombre egoísta separado de otros hombres y de la comunidad, es decir, no implica que tengan que (o puedan) ser explicados a la luz de alguna de estas dos caras que, según Atria, tiene el concepto de derecho subjetivo en la tradición liberal; Atria, F., Veinte años después. Neoliberalismo con rostro bumano, Catalonia, Santiago, 2013, p. 147-148. 
violación los individuos no estuvieren judicialmente amparados, ellos se encontrarían en una situación demasiado precaria frente a los poderes fácticos del Estado y sus agentes. Consecuentemente, la garantía judicial de estos derechos no debe ser considerada como la protección de un interés individual, sino como una condición para que sea posible el Estado de Derecho.

He aquí los auténticos derechos fundamentales civiles que, amparados directamente por estos Tribunales Superiores de Justicia, sirven a la función conservadora del derecho, que no es parte constitutiva de la democracia, sino una de las condiciones que la hacen posible.

Las disposiciones que consagran los llamados derechos civiles también expresan fragmentos de normas de competencia. Estas no confieren a los individuos derechos subjetivos que reflejan obligaciones, sino potestades de participación política cuyo ejercicio condiciona la validez (general o particular) de normas jurídicas creadas por actos de producción normativa de las autoridades públicas.

De las normas jurídicas producidas por estos actos (legislativos, administrativos o judiciales), así como de los actos mismos, se puede predicar validez o invalidez porque tales actos son normativos. Y se puede predicar validez con referencia a las mencionadas potestades de los individuos porque, mediante su ejercicio, ellos toman parte en las decisiones judiciales que invalidan general o particularmente normas jurídicas. Los individuos que ejercitan estas potestades aplican (no cumplen) las normas que las confieren.

Esta dimensión de los derechos fundamentales civiles está conceptualmente conectada con una parte del trabajo que realizan las Cortes de Apelaciones y la Corte Suprema cuando conocen y fallan las acciones de protección y de amparo, y asimismo con la actividad que realiza el TC cuando resuelve las acciones de inconstitucionalidad e inaplicabilidad.

Para comprender el sentido en que los denominados derechos civiles no son derechos subjetivos sino potestades de participación política, resulta indispensable descartar fundadamente que estas posiciones jurídicas sean conceptualmente separables de las acciones de inconstitucionalidad, inaplicabilidad, protección y amparo que la Constitución confiere, bajo ciertas condiciones, a los individuos. Esta idea se funda en la equivocada creencia que los denominados derechos civiles son siempre derechos subjetivos (garantizados por las mencionadas acciones constitucionales).

En lo que sigue me concentraré en el análisis de esta dimensión de los llamados derechos civiles y su relación con las funciones que, respecto del control de constitucionalidad de las normas legales, cumple el TC.

\section{LOS DERECHOS CIVILES COMO POTESTADES DE PARTICIPACIÓN POLÍTICA}

\subsection{La rigidez de la constitución, el control de constitucionalidad y el Tribunal Constitucional como legislador negativo}

La posición de supremacía de una constitución rígida significa que: (i) las normas constitucionales no puedan ser modificadas del mismo modo que las demás normas, y (ii) 
la conformidad con las normas constitucionales es una condición de validez de cualquier norma, de suerte que una norma que pretenda modificar la constitución es inválida ${ }^{40}$.

La incorporación de un catálogo de "derechos" fundamentales en una Constitución rígida únicamente expresa una decisión de autolimitación consistente en que la afectación de ciertos bienes (como la libertad personal, la libertad de conciencia y la igualdad) solo es posible mediante normas aprobadas con un acuerdo de la mayoría con la minoría, de suerte que toda norma que sin ser así aprobada pretenda modificar la Constitución es inválida. Algo distinto es que exista una garantía de que tales bienes no van a ser afectados. Dicha garantía solo existe cuando se prevé alguna forma de controlar que las normas jurídicas se ajusten a la Constitución ${ }^{41}$.

Desde que Kelsen mostró inmejorablemente la inexistencia de contradicción entre política y jurisdicción y que el acto de anular una norma es un acto de producción de signo negativo, el órgano encargado de controlar la constitucionalidad de las normas de inferior jerarquía puede ser justificadamente considerado un auténtico legislador negativo $^{42}$.

La principal objeción formulada en contra de la llamada jurisdicción constitucional es la llamada "contramayoritaria", en el entendido que aquella posee competencia para realizar un control sustantivo en cuya virtud sus decisiones se imponen a las adoptadas por el legislador elegido democráticamente. Pero este problema no se presentaría si la señalada competencia estuviera circunscrita a un control de la observancia de las reglas procedimentales de la democracia, asumiéndose una comprensión procedimental de la Constitución. ${ }^{43}$ Este es precisamente el signo distintivo de la propuesta kelseniana, cuya comprensión formal de la Constitución y de la jurisdicción constitucional se deriva del carácter exclusivamente formal atribuido a la validez (y por tanto a la constitucionalidad) de las normas jurídicas.

De acuerdo con Kelsen, la jurisdicción constitucional en relación con las normas de inferior jerarquía solo es posible cuando las normas materialmente constitucionales son también formalmente constitucionales. Esto significa que la decisión de anular una norma inconstitucional por razones de "contenido" no se fundamenta en la norma misma,

\footnotetext{
${ }^{40}$ Guastini, R., Op. cit., 2001, pp. 188-189 y 193. A estas dos cosas apunta respectivamente Kelsen cuando caracteriza la constitución en sentido formal y en sentido material. La primera expresa una decisión de autolimitación en cuya virtud las medidas que afectan a una determinada esfera de intereses solo son posibles en virtud de un acuerdo entre mayoría y minoría; Kelsen, H., De la esencia y valor de la democracia, KRK Ediciones, Oviedo, 2009a (original de 1929), pp. 140-142. Es el documento que contiene disposiciones según las cuales, las normas contenidas en él no pueden ser derogadas o modificadas como simples leyes sino solo bajo condiciones más difíciles. Estas disposiciones configuran la forma de la constitución y sirven para estabilizar las normas de la constitución en sentido material que, en cambio, constituyen el fundamento y estrato superior jurídico-positivo de todo orden jurídico estatal al regular la producción de normas jurídicas generales; Kelsen, H., Op. cit., 1991 (1960), pp. 232-233.

${ }^{41}$ Ver Kelsen, H., Op. cit., 2009 b (1931), pp. 292-293; Guastini, R., Op. cit., 2001, pp. 188-189 y 193 y Orunesu, C., Op. cit., 2012, p. 106.

${ }^{42}$ Kelsen, H., Op. cit., 2009b (1931), pp. 305-308 y 324-325 y nota No 11 del mismo trabajo.

${ }^{43}$ Así, Habermas, J., Facticidad y validez, Trotta, Madrid, 2008 (original de 1992), p. 337.
} 
sino en el "hecho" de no haber sido producida conforme al procedimiento de reforma constitucional. La jurisdicción constitucional consiste simplemente en que una norma debe ser anulada en su validez general (para todos los casos) o particular (para un caso concreto), porque el hecho concreto de su producción se encuentra en contradicción con la norma que regula ese hecho, y que por ello es una norma superior ${ }^{44}$.

El hecho de que el TC no reconozca como una de sus funciones la de legislar, arguyendo que se limita a constatar la contradicción entre una norma legal y la Constitución ${ }^{45}$, no impide concluir que efectivamente cumple esta función. Al respecto simplemente cabe distinguir, siguiendo a Peña, el "ethos explícito" del "ethos implícito" 46 que, en la especie, supone diferenciar lo que este tribunal dice que hace de lo que efectivamente hace.

Si la validez de una norma jurídica depende de que haya sido producida conforme a lo determinado en otra norma jurídica que entonces funda la validez de la primera ${ }^{47}$, la validez -y la constitucionalidad- general o particular de una norma cuya producción ha sido, por razones sustantivas, sustraída de la competencia de cualquier órgano diferente del facultado para reformar la Constitución, depende de que efectivamente haya sido producida por este órgano. Esto es lo que debe verificar el TC tanto en los casos de control abstracto como en los de control concreto.

Que el TC pueda ser visto como un garante de las reglas del juego democrático no oculta el carácter sustantivo de lo que tiene que decidir en todos los casos de control de constitucionalidad. Por mucho que el carácter formal de la validez jurídica sea enfatizado, no se puede desconocer que la norma jurídica que sirve de base al juicio de constitucionalidad aparece como una norma que determina los contenidos que la Constitución ha previsto excluir de las futuras normas para el caso que no se obtenga un acuerdo con la minoría.

Un punto de partida adecuado podría ser atender al hecho que cuando los efectos de las decisiones del TC se circunscriben al caso decidido, se sugiere que a la competencia de aquel no puede atribuirse un carácter legislativo ${ }^{48}$. Sin embargo, la circunstancia de

${ }^{44}$ Kelsen, H., Op. cit., 2009 b (1931), pp. 311-314.

${ }^{45}$ En efecto, aunque el tribunal afirma que la sentencia estimatoria de inconstitucionalidad que expulsa el precepto legal del ordenamiento jurídico produce generales efectos derogatorios, destaca que su labor no es en modo alguno la de legislar, sino solo constatar la irremediable contradicción entre un precepto legal y la Carta Fundamental; Ver considerandos vigésimo segundo y vigésimo séptimo de la sentencia rol $\mathrm{N}^{\circ}$ 1254-2008 (inconstitucionalidad).

46 Peña, C., “¿Qué hacen los civilistas?”, en Cuadernos de Análisis Jurídico, No 28, Universidad Diego Portales, Santiago, 1993, p. 13.

${ }^{47}$ Kelsen, H., Op. cit., 1991 (1960), p. 232.

${ }^{48}$ En este sentido, por ejemplo, Habermas afirma que la competencia concerniente al control concreto de normas (que dice relación con los casos en que los tribunales de instancia suspenden temporalmente un proceso para obtener, con motivo de algún asunto concreto, una decisión acerca de la constitucionalidad de una norma que se tiene que aplicar) es, junto con la competencia concerniente a los recursos de amparo, la menos problemática desde el punto de vista de la división de poderes. En tales casos el Tribunal constitucional actuaría en el sentido de una unificación y coherentización del derecho. La jurisprudencia constitucional que parte del caso particular se restringiría a la aplicación de normas constitucionales que se presuponen válidas. Por eso la distinción entre discursos de fundamentación de normas y discursos de aplicación de normas seguiría 
que la aplicabilidad de las normas válidas deba juzgarse en concreto con arreglo a las mismas normas de conformidad con las que se ha juzgado su validez en abstracto, nos da una pista en la dirección opuesta.

Del carácter concreto de las decisiones acerca de la aplicabilidad de normas generales no se sigue que tales decisiones deban ser consideradas como una actividad que no es en absoluto legislativa. Cuando se declara la inaplicabilidad de una norma, esta es invalidada aplicando la norma de competencia que define su modo de producción. Igualmente se realiza un acto de producción de signo negativo, aunque solo tenga efecto en determinado caso ${ }^{49}$. A la inversa, de la consideración del control abstracto de constitucionalidad como una actividad legislativa no se sigue que las decisiones que en este contexto adoptan los jueces constitucionales sean completamente independientes de las situaciones concretas de aplicación.

Se ha sostenido que la inaplicabilidad y la inconstitucionalidad reposan en la distinción entre enunciado normativo y norma. Mientras la primera permitiría detectar, en la aplicación de normas a casos, las interpretaciones del enunciado legal que infringen la Constitución, la segunda implicaría que el TC se pronuncia respecto del enunciado (no referente a las normas), de suerte que si el enunciado no admite interpretaciones conciliatorias con la Constitución, declararía su invalidez $z^{50}$.

El propio TC ha argumentado que, en la inaplicabilidad, la decisión ha de recaer en la conformidad o contrariedad con la Constitución que la aplicación de la norma impugnada puede tener en el caso concreto, y no en su contradicción abstracta y universal con la preceptiva constitucional, como ocurre con la inconstitucionalidad. Consecuentemente, mientras los efectos de la resolución que desaplica un precepto legal son relativos y conciernen a las partes del juicio o gestión en que inciden, el juicio de inconstitucionalidad expresa una comparación abstracta de manifiesta incompatibilidad. La ilegitimidad constitucional del precepto legal emana de su propio enunciado, sin referencia a una situación singular; y la sentencia estimatoria de inconstitucionalidad que

ofreciendo un criterio de deslinde (articulado en términos de lógica de la argumentación) de las tareas que legítimamente pueden cumplir la justicia y el poder legislativo. Habermas, J., Op. cit., 2008 (1992), p. 334.

${ }^{49}$ Esta afirmación no implica que se ignore la conocida distinción entre validez y aplicabilidad. Ocurre, sin embargo, que la expresión "aplicabilidad" no es usada en el sentido según el cual afirmar que una norma jurídica es aplicable significa afirmar la existencia de una norma jurídica prescriptiva, de acuerdo con ello la norma en cuestión debe ser aplicada a cierto caso; Bulygin, E, "Tiempo y validez" en Alchourrón, C. y Bulygin, E., Análisis lógico y derecho, CEPC, Madrid, 1991 (original de 1988), p. 196. En el sentido empleado, aplicabilidad significa "eficacia", entendida como un sinónimo de "vigencia" o "aptitud judicial", que se predica de una norma jurídica cuando esta tiene la disposición de ser aplicada en ciertas circunstancias. Los enunciados de eficacia no aluden entonces a una propiedad de la norma que pudiera ser considerada como causa de la aplicación, sino a que la correlación entre la norma y su aplicación es afirmada como existente en el presente. Como en este sentido, y en el contexto analizado, la aplicabilidad de una norma se juzga con arreglo a las mismas normas (cosntitucionales) conforme a las cuales se ha juzgado su validez, dicha aplicabilidad es, en términos kelsenianos, la validez singular de la norma mientras su inaplicabilidad es su anulación para determinado caso; ver nota $\mathrm{N}^{\circ} 27$ de este trabajo.

${ }^{50}$ Gómez, G., Las sentencias del Tribunal Constitucional y sus efectos sobre la jurisdicción común, Ediciones Universidad Diego Portales, Santiago, 2013, p. 56. 
expulsa el precepto del ordenamiento jurídico produce efectos generales y derogatorios ${ }^{51}$. De ello se sigue que no existe una relación causal entre ambos juicios (de inaplicabilidad e inconstitucionalidad) en términos que la inaplicación de un precepto provoque y convoque necesaria y obligatoriamente a una declaración de inconstitucionalidad. Una disposición declarada inaplicable puede perfectamente ser constitucional en abstracto y resultar aplicable a otros $\operatorname{casos}^{52}$.

En contra de esta descripción es, sin embargo, plausible sugerir que afirmar la inconstitucionalidad de una norma general equivale a decir que su aplicación sería incompatible con la norma o normas superiores, con arreglo a ellas su constitucionalidad se examina en todos los supuestos de interpretación y aplicación que han podido ser previstos $^{53}$. Y esto es precisamente lo que el TC concluye justo después de haber señalado que una disposición declarada inaplicable puede ser constitucional en abstracto. Valga transcribir la conclusión de manera textual en cuanto muestra bien que no es efectivo que la ilegitimidad constitucional del precepto legal emane, como se sostiene, de su propio enunciado sin referencia a una situación singular:

"Solo será inconstitucional si ninguna interpretación o posible hipótesis de aplicación de la disposición admite su sujeción a la Carta Fundamental" 54.

La cuestión es todavía más evidente si se atiende al hecho de que la declaración de inaplicabilidad de un precepto legal es un presupuesto procesal de su declaración de inconstitucionalidad, además de implicar la imposibilidad de que esta última se extienda más allá de lo resuelto previamente en las sentencias de inaplicabilidad ${ }^{55}$.

El TC se preocupa de puntualizar que si bien la declaración de inconstitucionalidad debe recaer sobre los mismos artículos de la Constitución invocados en las resoluciones

${ }^{51}$ Considerando vigésimo séptimo de la sentencia rol No $1254-2008$ (inconstitucionalidad).

52 Considerando vigésimo octavo de la sentencia rol N 1254-2008 (inconstitucionalidad).

53 Así razona, por ejemplo, Prieto Sanchís, L., Op. cit., 2000, pp. 445-446.

${ }^{54}$ Considerando vigésimo octavo de la sentencia rol No $1254-2008$ (inconstitucionalidad). El énfasis es mío.

${ }^{55}$ Considerando decimotercero de la sentencia rol N ${ }^{\circ} 1254-2008$ (inconstitucionalidad). A juicio del TC, las declaraciones de inconstitucionalidad e inaplicabilidad han sido vinculadas tanto en su relación de existencia como en su contenido. Por un lado, la declaración de inaplicabilidad es condición sine qua non para que el mismo precepto sea declarado inconstitucional. Por otro lado, la declaración de inconstitucionalidad debe fundarse únicamente en los preceptos constitucionales considerados transgredidos por la sentencia de inaplicabilidad previa que le da sustento. Al parecer del TC, la primera dimensión entrega una base de certeza respecto de los antecedentes que están en poder del tribunal para adoptar una decisión de la envergadura de expulsar el precepto del ordenamiento. Esta decisión no es automática, sin embargo, la vinculación entre ambas instituciones adiciona al examen de constitucionalidad la exigencia, no usual en el derecho comparado, de condicionar el control abstracto al control concreto, aun cuando se trata de dos facultades jurisdiccionales de distinta naturaleza. En este contexto, se admite que estas relaciones introducen inevitablemente el examen concreto de las sentencias que sirven de apoyo al proceso en el examen abstracto de constitucionalidad, y que la imposibilidad práctica de separar ambos controles se hace más evidente con la segunda dimensión de la relación entre ambos institutos; ver considerandos vigésimo noveno a trigésimo segundo de la sentencia rol $\mathrm{N}^{\circ} 1710-2010$ (inconstitucionalidad). 
previas de inaplicabilidad, debe considerarse que, como tal infracción ha recaído sobre la aplicación del precepto cuestionado en un caso concreto, el tribunal no puede limitarse a reproducir los mismos razonamientos y análisis efectuados en los casos concretos al ejercer el control abstracto ${ }^{56}$. Pero en la práctica ocurre que la inconstitucionalidad es declarada sobre la base de los mismos fundamentos que apoyaron la previa decisión de inaplicabilidad ${ }^{57}$.

En este escenario, parece más plausible sostener, como lo hace Gómez, que en vista que la acción de inconstitucionalidad solo procede si ha sido declarada previamente la inaplicabilidad del mismo precepto, es común que, al resolver la primera, el TC tome en cuenta la situación o situaciones concretas para las cuales declaró la segunda. Esto permitiría atisbar lo que parece ser la razón más poderosa para preferir los controles concretos frente a los abstractos, o para impulsar un control constitucional con notable preponderancia de aquellos. La fortaleza del control concreto derivaría de que para determinar si las leyes infringen la Constitución, y muy especialmente los derechos fundamentales, resulta primordial tener en cuenta la variedad de situaciones sociales a las que los preceptos legales se aplican ${ }^{58}$.

Esta lectura del modelo chileno de control de constitucionalidad de los preceptos legales no solo matiza el carácter abstracto que suele atribuirse al examen de constitucionalidad demostrando que, cualquiera sea la decisión legislativa en definitiva que se adopte, ella no será independiente del análisis de las situaciones concretas de aplicación. También difumina el carácter concreto que con frecuencia se predica del examen de aplicabilidad, pues la interpretación de la jurisdicción constitucional como un proceso gradual

${ }^{56}$ Considerando trigésimo tercero de la sentencia rol No $1710-2010$ (inconstitucionalidad).

57 En la sentencia rol $\mathrm{N}^{\mathrm{o}} 1254-2008$ (inconstitucionalidad), el TC resuelve que se declara que la expresión "gratuitamente" contenida en el inciso primero del artículo 595 del Código Orgánico de Tribunales (referida a la institución del abogado de turno) es inconstitucional, pero su decisión se funda literalmente en las mismas consideraciones que la sentencia del mismo tribunal, rol 755-2007 (inaplicabilidad), que había declarado inaplicable la misma expresión. La única diferencia reside en que en los considerandos finales de esta última sentencia se alude, por una parte, a las características del examen de inaplicabilidad (considerandos sexagésimo cuarto a sexagésimo sexto), y por otra parte, a las circunstancias particulares y precisas del caso concreto que, según el tribunal, permiten concluir que la exigencia del turno gratuito que se impone al abogado requirente, como consecuencia de la aplicación del mencionado artículo 595 en la gestión pendiente que se sigue ante la Corte Suprema, resulta contraria a la Constitución (considerandos sexagésimo séptimo a sexagésimo octavo).

58 Esto es así, por una parte, debido a que como es imposible anticipar la variedad y riqueza de situaciones, los controles que se fundan en casos permiten argumentar en función de ellos y así evitar que las leyes sean declaradas inconstitucionales cuando hay situaciones debidamente regidas por ellas, o que no lo sean por temor a dejar a otros casos sin norma. Además, porque la prosperidad de los debates constitucionales acerca de cuestiones acuciantes de la vida pública de un país y la posibilidad de tener discusiones públicas bien orientadas depende de que se diferencien los casos. Los debates respecto de la constitucionalidad de las leyes -sobre todo para garantizar derechos fundamentales- exigen argumentación y fundamentación diferente según las situaciones y posiciones en que se encuentran los individuos, aspecto que se fortalece debido a que lo enunciados constitucionales que consagran derechos fundamentales exigen altos niveles de concreción para decidir referente a las desviaciones de una ley o la tutela de derechos, y la concreción demanda tener en cuenta la variedad de situaciones a las que se aplican las leyes; Gómez, G., Op. cit., 2013, pp. 28-29. 


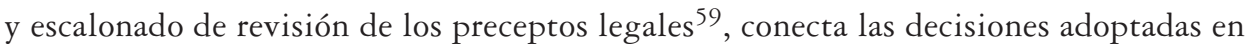
sede de aplicabilidad con las decisiones que se adoptan en sede de constitucionalidad, de suerte que entre ambas existe una genuina interacción.

\subsection{La reconstrucción de los derechos civiles como potestades de participación politica}

Que el control de constitucionalidad de las normas no es una consecuencia necesaria del hecho que la Constitución haya sustraído ciertas esferas de intereses de la competencia de la legislatura ordinaria, es algo que puede considerarse más o menos evidente. Pero mucho menos evidente, aunque cierto, es que de ninguna de estas dos cosas se sigue que los individuos sean titulares de determinadas posiciones jurídicas subjetivas. Entendidos como potestades de participación política, los derechos civiles solo entran en juego cuando el control de la constitucionalidad de las normas infraconstitucionales se hace depender de la voluntad de los individuos.

Esto significa, como precisa Kelsen, que cuando la Constitución en sentido material excluye determinados contenidos de las futuras normas, el típico catálogo de derechos y libertades fundamentales que es parte integrante de las constituciones modernas no es, en lo esencial, si no una tentativa de impedir que las normas -que por ejemplo lesionen la libertad personal, la libertad de conciencia o la igualdad- no puedan producirse. La eficacia de esta tentativa depende de la posibilidad de anular tales normas, sin que en ello esté implicado el otorgamiento de ningún derecho subjetivo (reflejo o técnico) ${ }^{60}$.

Los titulares de estas posiciones jurídicas no tienen un derecho subjetivo a que las autoridades públicas se abstengan de producir normas inválidas o inaplicables, sino la potestad de tomar parte en las decisiones judiciales de invalidación o desaplicación de las normas jurídicas producidas por dichas autoridades. Cuando estas normas jurídicas son de carácter general, la participación de los individuos es jurídicamente posible solo en cuanto ellos son titulares de las acciones de inconstitucionalidad e inaplicabilidad.

\footnotetext{
59 Ibid., pp. 29-30.
}

${ }^{60}$ Kelsen, H., Op. cit., 1991 (1960), p. 234. Según Kelsen, aunque las disposiciones constitucionales que declaran que ciertos "derechos" (como la libertad personal, la libertad de conciencia o la igualdad) se encuentran garantizados aparezcan como "prohibiciones" de violar tales "derechos" mediante normas de inferior jerarquía, no constituyen realmente derechos reflejos ni derechos subjetivos en sentido técnico porque no consisten en imponer a los órganos jurídicos la obligación jurídica de no dictar tales normas. Estas posiciones jurídicas solo constituyen un derecho en el sentido de un poder jurídico cuando el orden jurídico otorga al individuo afectado por una norma inconstitucional un poder para iniciar, con una queja, el procedimiento dirigido a la supresión de dicha norma. Dando por hecho que obligar a un órgano legislativo colectivo a no dictar normas inconstitucionales es casi imposible por motivos técnicos, Kelsen admite que sería posible que un tribunal especial impusiera penas específicas (como la privación del cargo o la pérdida de los derechos políticos) a quienes deban promulgar tales normas. En tal caso existiría una prohibición jurídica de participar en dicha promulgación, pero el poder jurídico para iniciar el proceso conducente a la imposición de esas sanciones, por regla general, no estaría reservado a los individuos afectados por la norma inconstitucional; Ibíd, pp. 150-156. Por lo demás, si en esta hipótesis fuere posible afirmar, como sostiene Kelsen, la existencia de auténticas prohibiciones jurídicas dirigidas a los órganos estatales y los correspondientes derechos subjetivos, sería sumamente objetable su indeterminación. 
Por lo mismo, las disposiciones constitucionales que consagran los denominados derechos civiles expresan apenas un fragmento de las normas de competencia que confieren a los individuos estas potestades de participación. De suerte que estas normas no constituyen el significado de una disposición, sino el significado de la combinación de al menos cinco disposiciones normativas:

(i) La disposición que simplemente declara el aseguramiento de ciertos bienes, como "derecho a la vida", "igualdad ante la ley" o "libertad de conciencia" (artículo 19 números $1^{\circ}, 2^{\circ}$ y $6^{\circ}$ de la Constitución).

(ii) Una disposición que condiciona la validez general o particular de toda norma jurídica a su conformidad con la Constitución (artículo 7 de la Constitución).

(iii) La disposición que condiciona la validez general o particular de la reforma de la Constitución a la obtención de un acuerdo de la mayoría con la minoría y, por tanto, a su aprobación con un quórum más elevado que el previsto para la modificación de las demás disposiciones del orden jurídico (artículo 127 inciso segundo de la Constitución).

(iv) La disposición que confiere competencia al Tribunal Constitucional para declarar la invalidez general (inconstitucionalidad) o la invalidez particular (inaplicabilidad) de las normas producidas por las autoridades públicas que, pudiendo afectar los bienes mencionados en el número (i), no hayan sido aprobadas con el quórum previsto para reformar la Constitución (artículo 93, números 6 y 7 de la misma Constitución).

(v) La disposición que confiere a los individuos la potestad de requerir a ese tribunal que declare la inconstitucionalidad o la inaplicabilidad recién mencionadas (artículo 93 incisos undécimo y duodécimo de la Constitución).

Lo anterior muestra bien por qué las acciones de inaplicabilidad e inconstitucionalidad no deben ser entendidas como una garantía de derechos subjetivos. Ellas no persiguen directamente el cumplimiento de una obligación estatal incumplida ni la ejecución de la sanción prevista para el incumplimiento de dicha obligación, sino la participación de los individuos en las decisiones acerca de lo que no cuenta como derecho. Estas acciones forman parte del concepto de los derechos civiles entendidos como potestades de participación política.

Desde esta perspectiva deben ser leídas las decisiones del TC respecto de estas acciones constitucionales. Y el hecho que la jurisprudencia de este tribunal insista en que su ejercicio, conocimiento y resolución se vincula con la protección de derechos fundamentales que reflejan obligaciones estatales y que, en este orden, se argumente profusamente en torno a su violación, no cambia el hecho que la competencia de este tribunal (limitada a declarar que determinado precepto legal no vale, es decir, que no cuenta como derecho para determinado caso o para todos los casos) no comprenda la protección directa de estas posiciones jurídicas subjetivas ${ }^{61}$.

${ }^{61}$ Ver por ejemplo las sentencias del conocido "Caso Isapres" que declaran inaplicable y posteriormente inconstitucional el artículo 38 ter de la Ley $\mathrm{N}^{\circ}$ 18.933; rol No 976-2007 (inaplicabilidad) y rol No 17102010 (inconstitucionalidad). Así lo ha reconocido, aunque con matices, Marisol Peña, actual ministra del 


\section{3. ¿Limites sustantivos a la producción de normas?}

La relativización de la diferencia que pretendidamente existe entre el control concreto y abstracto de constitucionalidad y, por tanto, entre el objeto y efecto de las declaraciones de inaplicabilidad e inconstitucionalidad encuentra también fundamento en dos características salientes de las disposiciones constitucionales que consagran los llamados derechos fundamentales civiles: su indeterminación y la conflictividad de sus contenidos ${ }^{62}$.

En razón de que las disposiciones constitucionales que consagran posiciones jurídicas subjetivas suelen ser, en buena medida, indeterminadas y sus contenidos tendencialmente conflictivos: (i) su interpretación, y el subsiguiente control abstracto de constitucionalidad de las normas tiene que llevarse a cabo teniendo en cuenta los posibles supuestos de aplicación ${ }^{63}$, y (ii) tanto su interpretación como el control concreto de constitucionalidad

TC, al señalar que este:"(N)o ha sido instituido como protector directo de los derechos fundamentales, a diferencia de magistraturas similares de otros países, que tienen competencia en materia de amparo o de tutela de tales derechos. Ello porque el Constituyente de 2005 -que modificó significativamente sus atribuciones- no traspasó el conocimiento y fallo de los recursos de protección y de amparo (o habeas corpus) desde las Cortes de Apelaciones al Tribunal Constitucional; Peña, M., "Aplicación de los derechos económicos, sociales y culturales por el Tribunal Constitucional chileno”, en Nogueira, H. (coord.), Dogmática y aplicación de los derechos sociales, Librotecnia, Santiago 2010, p. 302 (el énfasis es mío). A continuación, la autora añade que, no obstante lo dicho, cabe observar que el $85 \%$ de la actividad del TC se destina a la decisión de acciones de inaplicabilidad, y que un rápido examen de su contenido permite sostener que lo usual es que se destinen a impugnar preceptos legales que se estiman violatorios de derechos consagrados en la Constitución o en tratados internacionales ratificados por Chile que se encuentran vigentes. A partir de ello, concluye que bien se puede afirmar que la inaplicabilidad ha ido derivando, en la práctica, en una especie de amparo de los derechos fundamentales, complementaria de los recursos de protección y amparo tradicional, constituyendo una verdadera mutación constitucional. En esta conclusión hay dos errores: (i) No se advierte que los tradicionales recursos a los que la autora se refiere, además de servir para tutelar directamente auténticos derechos subjetivos fundamentales, pueden cumplir exactamente la misma función que las acciones de inaplicabilidad y de inconstitucionalidad. La diferencia solo reside en que las normas cuya constitucionalidad se examina no son generales sino particulares; y (ii) No se advierte que la inaplicabilidad no puede ser considerada como una instancia de protección directa de derechos fundamentales en la medida en que el juicio de inaplicabilidad se fundamenta, tanto como el de inconstitucionalidad, en normas de competencia, y no en normas regulativas. La diferencia reside únicamente en que la aplicación de la norma cuya aplicabilidad se examina es cierta y evidentemente más inminente que la aplicación de las normas que son examinadas en sede de inconstitucionalidad.

${ }^{62} \mathrm{Si}$ no me equivoco, a estas mismas características se refiere Gómez cuando se alude a la particular deficiencia de la justificación interna de las sentencias constitucionales a partir de enunciados constitucionales que consagran derechos. Estos enunciados no serían suficientes por sí mismos como premisas de una decisión constitucional, debido a que exigen crecientes grados de especificidad o razones adicionales y a que estas inferencias son en muchos casos de alta complejidad y debatidas; Gómez, G., Op. cit., 2013, p. 30.

${ }^{63}$ En la misma dirección Gómez afirma que como para resolver cuestiones relativas a la especificación de estas disposiciones y a la resolución de conflictos entre derechos fundamentales requerimos razones adicionales, las jurisdicciones constitucionales con modelos de control concreto, o aquellas en que estos tienen preponderancia, nos proveen de razones derivadas de la argumentación según los casos y ello enriquece y facilita el debate; Ibíd. 
que conforme a dicha interpretación se realiza, involucran, en una medida importante, creación de derecho.

En sentido contrario, el TC ha sugerido que es posible descubrir la interpretación correcta de los preceptos legales sometidos a control. Así por ejemplo, afirma:

"Que, por otra parte, como lo ha venido sosteniendo este tribunal en diversos pronunciamientos, la acción de inaplicabilidad dice relación con el examen concreto de si un determinado precepto legal invocado en una gestión judicial pendiente y correctamente interpretado producirá efectos o resultados contrarios a la constitución" 64 .

En este caso se impugnaba específicamente el inciso primero del artículo 595 del Código Orgánico de Tribunales que establece la institución del llamado "abogado de turno", arguyendo que su aplicación, en el caso analizado, contravenía diversos derechos fundamentales, esencialmente la igualdad ante la ley, la igualdad ante las cargas públicas y la libertad de trabajo y comercio ${ }^{65}$.

El TC acogió el requerimiento de inaplicabilidad pero solo en cuanto a declarar inaplicable, en la causa pendiente seguida ante la Corte Suprema, la expresión "gratuitamente" a que alude el precepto ya mencionado. Para ello argumentó que si bien no aparece que el requirente se haya visto privado de su libertad de trabajo ni de su capacidad de ejercer privadamente su profesión con las dos designaciones (como abogado de turno) acreditadas, resulta evidente que la ejecución de dichas labores no ha podido sino producir un menoscabo y un detrimento que debe ser debidamente compensado por el Estado. Y que por tanto, la exigencia del turno gratuito que se impone al abogado requirente, como consecuencia de la aplicación del precepto legal impugnado, resulta contraria a la Constitución, particularmente a su artículo 19 números 2, 20 y 16, esto es, a la igualdad ante la ley, la igualdad ante las cargas públicas y la libertad de trabajo ${ }^{66}$.

Prueba incontrastable de que no existe una única interpretación correcta del señalado precepto a la luz de las disposiciones constitucionales involucradas, es el hecho que dos de los jueces que concurrieron al fallo formularon sendas prevenciones ${ }^{67}$. Y los

${ }^{64}$ Considerando sexagésimo cuarto de la sentencia rol No 755-2007 (inaplicabilidad). El énfasis es mío.

${ }^{65}$ Considerandos sexto y séptimo de la sentencia rol No $755-2007$ (inaplicabilidad).

${ }^{66}$ Considerandos sexagésimo séptimo y sexagésimo octavo de la sentencia rol No 755-2007 (inaplicabilidad),

67 Según uno de ellos, la inaplicabilidad debía declararse, pero no porque ella impusiere una carga personal gratuita sino porque la ley no ha determinado con suficiente precisión el alcance de la obligación que puede imponerse a los abogados de defender gratuitamente a las personas sin recursos. A su juicio, no se respetaría la garantía de legalidad en la imposición de cargas públicas que emana del artículo 19 números 2 y 20, pero también del artículo 22 inciso tercero, cuando dispone que las "demás cargas personales que imponga la ley son obligatorias en los términos y formas que esta determine”. Tal falta de determinación de la ley, con la consiguiente amplia discrecionalidad judicial del artículo 595 inciso primero del Código Orgánico de Tribunales, es la que da por resultado en la gestión pendiente una aplicación de la ley que produce efectos contrarios a la Constitución. Según otro de los ministros del TC, la inaplicabilidad debería extenderse a la integridad del precepto que se impugna y no exclusivamente a la expresión "gratuitamente", 
numerosos casos similares apoyan la conclusión de que las normas de competencia que confieren a los individuos las potestades de participación política que aquí se analizan, condicionan la validez general o particular de las normas producidas por las autoridades públicas, en la precisa medida en que el ejercicio de dichas potestades puede tener el efecto de invalidarlas o desaplicarlas por no haber sido producidas del modo definido para reformar la constitución. No porque ellas realmente establezcan límites sustantivos a la competencia normativa del Estado excluyendo determinados contenidos de las futuras normas.

Tales límites o contenidos resultan, en cambio, determinables y su determinación depende de: (i) un acto de voluntad formal de un individuo con potestad para requerir que se declare por un tribunal la inconstitucionalidad general o particular de las normas producidas por las autoridades públicas y, (ii) un acto de voluntad formal de jueces con potestad para determinar el contenido preciso de los señalados límites ${ }^{68}$.

Desde esta perspectiva, en los derechos civiles no está implicada la idea de un interés individual que triunfa frente a (o en contra de) las aspiraciones comunitarias, ni la del hombre egoísta que exige el respeto de su derecho sin que importe la voluntad de la mayoría ${ }^{69}$. La pretensión de que los llamados derechos civiles son derechos subjetivos que constituyen auténticos límites sustantivos ${ }^{70}$ a la competencia normativa de

entre otras razones, porque que dicho precepto es absolutamente contrario a la libertad de trabajo. En su opinión: (i) la disposición objetada pugna con el mandato que emana del artículo $19 \mathrm{~N}^{\circ} 3$, que atribuye a toda persona el derecho a defensa jurídica y confía a la ley su satisfacción, y que corresponde al Estado y no a los particulares; (ii) el único sustento de la institución del "abogado de turno" se hace descansar en su eventual carácter de carga personal derivada del artículo 22 inciso tercero de la Constitución, sin embargo, los deberes constitucionales que dicha norma impone recaen, según el caso, en todo habitante de la república o todos los chilenos, destacando la generalidad o universalidad de los mismos, atributos contradichos por el carácter especial y reducido a un grupo de la población que reviste la imposición comentada, constituyendo así una carga personal no autorizada por la Constitución; y (iii) es evidente que la defensa obligatoria que se impone a un abogado es absolutamente contraria a la libertad de trabajo consagrada en el artículo 19 $\mathrm{N}^{\circ} 16$, tanto en su manifestación de libre elección como en el de la libre contratación en cuanto se trata de un servicio forzado, cuya elusión apareja graves sanciones

${ }^{68}$ En este sentido, resulta plausible concluir que es posible que la indeterminación del contenido de estos "derechos" responda a una elección consciente de delegar en otras instancias normativas el poder de reducir la indeterminación; Comanducci, P., Hacia una teoría analítica del derecho. Ensayos escogidos, CEPC, Madrid, 2010, p. 89, o que el preciso propósito de ciertas reglas sea conferir potestad a los intérpretes para elaborar los resultados sobre la base de factores que no se hallan contenidos en la regla, atendido que la propia regla exige desde su núcleo que el intérprete precise aquello que no ha sido determinado por ella. Encadenar al intérprete a otras reglas parece auto-derrotante, puesto que considerar a una regla que confiere potestades como sujeta a las exigencias privativas de potestades de otras reglas equivale a considerar de potestades como necesariamente sujeta a la privación de potestades; Schauer, F., Op. cit., 2004 (1991), pp. 292-293.

${ }^{69}$ Como sugiere se sugiere en Atria, F., Ob cit, 2004, pp. 51-52 y Ob cit, 2013, pp. 147-148.

${ }^{70} \mathrm{La}$ tesis de que los derechos civiles constituyen límites sustantivos a la producción de normas tampoco puede justificarse bajo la consideración de que aquellos son inmunidades o libertades, dado que estas posiciones jurídicas se caracterizan por la ausencia una norma que, respectivamente, sujete u obligue al individuo de que se trata. No habiendo norma no puede pretenderse la existencia de límite alguno. Hart, por ejemplo, considera que los derechos constitucionalmente garantizados son inmunidades usualmente reclamables judicialmente que, conferidas por normas de "incompetencia", impiden cambios legales adversos; 
las autoridades públicas sobrepasa los límites del derecho objetivo, confundiendo las protecciones del derecho con los bienes (o intereses) objeto de su protección ${ }^{71}$.

Esto no implica, sin embargo, que sea cierto que las disposiciones del artículo 19 de la Constitución chilena no sean normas que satisfagan los requisitos de una norma jurídica ${ }^{72}$. Es cierto que se trata de normas cuya aplicación no adjudica el conflicto porque no expresan concepciones sino conceptos que los jueces deben complementar ${ }^{73}$. Pero precisamente por eso es que se trata de normas de competencia que confieren a los individuos la potestad de tomar parte en el proceso en que los jueces constitucionales deciden lo que no cuenta como derecho.

Entendidos como potestades de participación política, tiene sentido afirmar, como lo hace Kelsen, que el catálogo de los denominados derechos fundamentales y libertades públicas ha dejado de ser un instrumento de protección del individuo frente al Estado para convertirse en un medio para la protección de una minoría cualificada frente a la mera mayoría absoluta, entendida la minoría como una pieza fundamental de la democracia y concebida esta última como un método que se dirige fundamentalmente a la consecución de compromisos entre mayoría y minoría ${ }^{74}$. Como mientras más vigorosa es la minoría más tiende la política de la democracia hacia una política del compromiso, ${ }^{75}$ los derechos civiles no protegen los intereses de la minoría, sino la posibilidad de que esta influya en la producción del orden jurídico.

H.L.A., "Legal Rights" en Essays on Bentham. Studies in Jurisprudence and Political Theory, Oxford University Press, New York, 1982, pp. 190-191. Sin embargo, bastante tiempo antes había admitido que tanto la inmunidad como la libertad son casos en los cuales el derecho reconoce "negativamente" la elección de un individuo porque "no hay" norma que interfiera si el individuo opta por conservar su posición jurídica inalterada (inmunidad) o por realizar o por omitir alguna acción (libertad); Hart, H.L.A., "Definición y teoría en la ciencia judicial", en Derecho y moral. Contribuciones a su análisis, Depalma, Buenos Aires 1962 (original de 1953), pp. 118-119 y nota $\mathrm{N}^{\circ} 14$ del mismo trabajo. Al respecto, debe recordarse que, en el modelo hohfeldiano, la posición de inmunidad -en el grupo de las posiciones de potestad, sujeción, inmunidad, e incompetencia- ocupa exactamente el mismo lugar que -en el grupo de las posiciones de derecho, deber, libertad y no derecho"- ocupa la posición de libertad, al punto que el propio Hohfeld, manifiesta que la inmunidad es la libertad de una persona frente a la potestad jurídica o contralor jurídico de otro, con respecto de una relación jurídica; Hohfeld, W., Op. cit., 1992 (1913), p. 81. Es muy probable que en razón de lo anterior algunos autores entiendan a los derechos civiles como "libertades" que preceden al Estado y, al mismo tiempo, como normas de competencias negativas (delimitaciones) relativas al poder del Estado; ver por ejemplo, Böckenförde, E., Escritos sobre Derechos Fundamentales, Nomos Verlagsgessellschaft, BadenBaden, 2001 (original de 1993), pp. 48-49.

${ }^{71}$ Es el clásico error descrito por Kelsen consistente en poner de manifiesto lo que el derecho (objetivo) protege o reconoce, es decir, un factor de carácter sustancial, en lugar de la protección o forma que interesa al jurista; ver Kelsen, Problemas capitales de la teoría jurídica, Porrúa, México D.F., 1987 (original de 1923), pp. 510 y 539 .

${ }^{72}$ Esto es afirmado por Atria, F., "El derecho y la contingencia de lo político", en Revista Derecho y Humanidades, $\mathrm{N}^{\circ} 11,2005$, p. 27.

73 Ibid., pp. 27-28.

${ }^{74}$ Kelsen, H, 2009a (1929): 139-142.

${ }^{75}$ Ibid., pp. 227-228. 


\section{LOS DERECHOS CIVILES Y POLÍTICOS COMO "POTESTADES FUNDAMENTALES"}

La reconstrucción de los derechos civiles que aquí se propone permite resolver el problema de su vinculación con los denominados derechos políticos.

Con los primeros, los individuos toman parte en las decisiones de invalidación de las normas jurídicas producidas por autoridades públicas. Mediante los segundos, los individuos participan en las decisiones acerca de creación, modificación y derogación de estas mismas normas. El ejercicio de los primeros limita la competencia normativa de las autoridades públicas condicionando la validez (general o particular) de las normas por ellas producidas. El ejercicio de los segundos condiciona la validez de estas mismas normas porque, en un sistema democrático, las autoridades públicas son competentes para producir normas jurídicas que obligan a los sujetos sometidos al derecho, precisamente porque dichas autoridades son elegidas por el sufragio de los titulares de los denominados derechos políticos.

Justamente porque ni los unos ni los otros son derechos subjetivos es que ambos son políticos ${ }^{76}$. El conjunto de estas posiciones jurídicas subjetivas puede denominarse "potestades fundamentales", toda vez que, a diferencia de los auténticos derechos fundamentales, son constitutivos de la democracia.

Esta lectura permite refutar la división de la ciudadanía propuesta por Marshall, al menos en lo que se refiere a su descomposición en las partes civil y política, así como la conclusión de que los tribunales de justicia y el Parlamento son instituciones que se vinculan a diferentes clases de derechos ${ }^{77}$. También permite relativizar la ya clásica división de la Constitución en dos partes (orgánica y dogmática) en la medida en que la concepción de estas como referidas, respectivamente, a la regulación y a la limitación del poder estatal, sin matices, oscurece el sentido en que los llamados derechos civiles son potestades de participación política.

Las potestades fundamentales (los derechos civiles y políticos) están necesariamente vinculados a la llamada parte orgánica de la Constitución. Ellas sirven a la función de creación y transformación del derecho en el mismo proceso en el que los tribunales con jurisdicción constitucional actúan como legisladores negativos, como consecuencia de ello, y a diferencia de lo que comúnmente se cree, no protegen directamente derechos fundamentales.

${ }^{76}$ La tesis que aquí se defiende debe ser bien distinguida de la propuesta raziana que también atribuye un significado político a los derechos civiles. Comparto la afirmación de este autor según la cual cualquier noción de que el hecho de que se traten temas relacionados con los derechos individuales excluye a la política se basa en un profundo malentendido acerca de la naturaleza de los derechos en general y de los derechos civiles y políticos en particular. Sin embargo, mi tesis es radicalmente diferente porque, como el mismo Raz lo admite, su interpretación hunde sus raíces en la teoría del interés. A su parecer, la razón por la cual los derechos civiles y políticos involucran inevitablemente a los tribunales en políticos porque aquellos combinan temas de interés individual con cuestiones de interés público, como consecuencia de lo cual involucran inevitablemente a los tribunales en política; Raz, J., La ética en el ámbito público, Gedisa, Barcelona, 2001 (original dde 1994), pp. 69-70. Mientras, mi punto de vista rechaza la teoría del interés y cualquier otra que confunda la protección del derecho con el objeto de su protección; ver nota $\mathrm{N}^{\circ} 70$.

${ }^{77}$ Marshall, T.H., Ciudadanía y clase social. Alianza. Madrid 1998 (original de 1950), pp. 22-23. 


\section{Bibliografía}

Alchourrón, C y Bulygin, E., "La concepción expresiva de las normas", en Alchourrón, C., y Bulygin, E., Análisis lógico y derecho, CEPC, Madrid, 1991 (original de 1981): 121-153. , "Definiciones y normas", en Alchourrón, C y Bulygin, E., Análisis lógico y derecho, CEPC, Madrid, 1991 (original de 1983): 439-463.

Aldunate, E., Derechos fundamentales, Legal Publishing, Santiago, 2008.

Alexy, R., Teoría de los derechos fundamentales, CEPC, Madrid, 2007 (original de 1984).

Atienza, M y Ruiz Manero, J., Las piezas del derecho, Ariel, Barcelona, 2004.

Atria, F., "Existen los derechos sociales", en Doxa, Discusiones: Derechos sociales, No 4, 2004: 15-59.

, Atria, F., "El derecho y la contingencia de lo político", en Revista Derecho y Humanidades, $\mathrm{N}^{\circ} 11,2005: 19-39$.

, Veinte años después. Neoliberalismo con rostro bumano, Catalonia, Santiago, 2013.

Austin, J.L., Cómo hacer cosas con palabras, Paidós, Barcelona 1971 (original de 1962).

Böckenförde, E., Escritos sobre Derechos Fundamentales, Nomos Verlagsgessellschaft, BadenBaden, 2001 (original de 1993).

Bulygin, E., "El concepto de eficacia", en VV.AA, Validez y eficacia del derecho, Astrea, Buenos Aires, 1965: 23-47.

, "Tiempo y validez”, en Alchourrón, C. y Bulygin, E., Análisis lógico y derecho, CEPC, Madrid, 1991 (original de 1982): "Sobre las normas de competencia”, en Alchourrón, C. y Bulygin, E., Análisis lógico y derecho, CEPC, Madrid, 1991 (original de 1988): 485-498.

Comanducci, P., Hacia una teoría analítica del derecho. Ensayos escogidos, CEPC, Madrid, 2010.

Cruz Parcero, J, El concepto de derecho subjetivo, Fontamara, México, 2007.

Ferrajoli, L., "Las garantías constitucionales de los derechos fundamentales", en Doxa, № 29, 2006: 15-31. Traducción de Alí Losada.

, "Derechos fundamentales", en Ferrajoli, VV.AA, Los fundamentos de los derechos fundamentales, Trotta, Madrid, 2007 (original de 2001):19-56.

, Principia iuris. Teoría del derecho y de la democracia, Trotta, Madrid, 2011 (original de 2007).

Ferrer, J., Las normas de competencia. Un aspecto de la dinámica jurídica, CEPC, Madrid, 2000.

Gómez, G., Derechos fundamentales y Recurso de protección, Ediciones Universidad Diego Portales, Santiago, 2005.

, Las sentencias del Tribunal Constitucional y sus efectos sobre la juridisdicción común, Ediciones Universidad Diego Portales, Santiago, 2013.

Guastini, R. Distinguiendo. Estudios de teoría y metateoría del derecho, Gedisa, Barcelona, 1999 (original de 1996).

_ Estudios de teoría constitucional, Fontamara, México D.F., 2001.

Habermas, J., Facticidad y validez, Trotta, Madrid, 2008b (original de 1992).

HART, H.L.A., "Definición y teoría en la ciencia judicial", en Derecho y moral. Contribuciones a su análisis, Depalma, Buenos Aires 1962 (original de 1953): 93-130.

"Legal Rights" en Essays on Bentham. Studies in Jurisprudence and Political Theory, Oxford University Press, New York, 1982.

_ El concepto de derecho, Abeledo-Perrot, Buenos Aires, 2009 (original de 1961).

Hohfeld, W., Conceptos jurídicos fundamentales, Fontamara, México D.F, 1992 (original de 1913). Kelsen, H., Teoría pura del Derecho, (2a edición), Porrúa, México D.F.,1991 (original de 1960). , De la esencia y valor de la democracia, KRK Ediciones, Oviedo, 2009a (original de 1929). , “QQuién debe ser el defensor de la Constitución?”, en Schmitt, Carl y Kelsen, Hans,

La polémica Schmitt/Kelsen sobre la justicia constitucional: El defensor de la Constitución versus 
¿Quién debe ser el defensor de la Constitución?, Tecnos, Madrid, 2009b (original de 1931): 289-366.

MAC Clure, L., "Tribunal Constitucional y los derechos. La discusión pendiente”, en Sierra, L y Mac-Clure, L, Frente a las mayorías. Leyes supramayoritarias y Tribunal Constitucional en Chile, CEP, CIEPLAN, Libertad y Desarrollo, Proyectamérica y PNUD, Santiago, 2011.

Marshall, T.H., Ciudadanía y clase social. Alianza. Madrid 1998 (original de 1950).

Nino, C.S., Introducción al análisis del derecho, Astrea, Buenos Aires, 1980.

Orunesu, C., Positivismo Jurídico y sistemas constitucionales, Marcial Pons, Madrid, 2012.

PeÑA, C., "¿Qué hacen los civilistas?", en Cuadernos de Análisis Jurídico, $\mathrm{N}^{\circ} 28$, Universidad Diego Portales, Santiago, 1993.

PEÑA, M., "Aplicación de los derechos económicos, sociales y culturales por el Tribunal Constitucional chileno", en Nogueira, H. (coord.), Dogmática y aplicación de los derechos sociales, Librotecnia, Santiago 2010: 299-318.

Prieto Sanchís, L., "La limitación de los derechos fundamentales y la norma de clausura en el sistema de libertades", en Derechos y libertades, N 8, enero/junio, 2000: 429-468. , Apuntes de Teoría del Derecho, Trotta, Madrid, 2009.

RAZ, J., Razón práctica y normas, CEPC, Madrid, 1991 (original de 1975). , La ética en el ámbito público, Gedisa, Barcelona, 2001 (original de 1994).

Ross, A, “Sobre los conceptos de 'Estado' y 'Órganos del Estado' en Derecho Constitucional”, en Ross, A, El concepto de validez y otros ensayos, Fontamara, México, 1991 (original de 1961): 73-92.

, Lógica de las normas, Colmares, Granada, 2000 (original de 1968).

Ruiz-TAgle, P., "Una visión democrática y liberal de los derechos fundamentales para la constitución chilena del bicentenario", en Bordalí, A (ed.), Justicia Constitucional y derechos fundamentales. Lexis Nexis, Santiago, 2006:69-128.

, "Un proyecto constitucional para la generación del bicentenario: Igualdad y derechos sociales y económicos en Chile”, en Revista de Derecho y Humanidades, N 15, 2009: 17-35.

Schauer, F., Las reglas en juego, Marcial Pons, Madrid, 2004 (original de 1991).

SEARle, J., La construcción de la realidad social, Paidós, Barcelona, 1997 (original de 1995). , Actos de habla. Ensayo de Filosofía del Lenguaje, Cátedra, Madrid, 2007 (original de 1969).

Wittgenstein, L., Investigaciones filosóficas, Crítica, Barcelona, 2008 (original de 1953).

Wright (Von), G., Norma y acción. Una investigación lógica, Tecnos, Madrid, 1970 (original de 1963).

ZAPATA, P., Justicia constitucional. Teoría y práctica en el derecho chileno y comparado, Editorial Jurídica de Chile, Santiago, 2008. 
